\title{
CORRECTION
}

\section{Correction to: The role of daily need crafting in daily fluctuations in adolescents' need-based and affective experiences}

\author{
Nele Laporte $^{1} \cdot$ Bart Soenens $^{1} \cdot$ Nele Flamant $^{1} \cdot$ Maarten Vansteenkiste $^{1} \cdot$ Elien Mabbe $^{1} \cdot$ Katrijn Brenning $^{1}$
}

Published online: 3 February 2022

(c) Springer Science+Business Media, LLC, part of Springer Nature 2022

Correction to: Motivation and Emotion

https://doi.org/10.1007/s11031-021-09921-2

The original version of this article unfortunately contained a mistake in Fig. 1. Figures 1 and 2 image are same. The correct Fig. 1 is given below.

The original article has been corrected.

The original article can be found online at https://doi.org/10.1007/ s11031-021-09921-2.

Nele Laporte

NeleLeen.Laporte@Ugent.be

1 Department Developmental, Personality and Social

Psychology, Ghent University, Henri Dunantlaan 2,

B-9000 Ghent, Belgium 
$.50(.047)^{\star \star \star /} .21(.051)^{\star \star \star}$

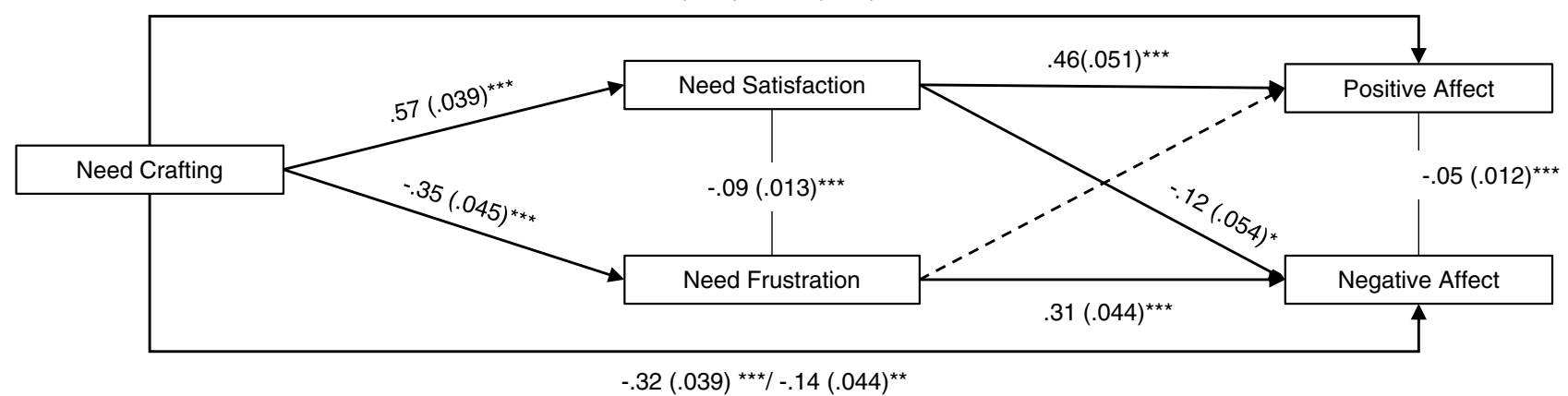

Note. Coefficients shown are unstandardized path coefficients with standard errors reported between brackets. ; direct effects after adding need-based experiences are reported after the slash "/, original direct effects are reported before the slash "/”; *** $p<.001 .^{* *} p<.01 .^{*} p<.05$

Fig. 1 Within-person level results of a multi-level mediation model of daily need crafting on daily affective experiences through daily needbased experiences

Publisher's Note Springer Nature remains neutral with regard to jurisdictional claims in published maps and institutional affiliations. 